\title{
LA INSATISFACCIÓN CON LA DEMOCRACIA EN EL MÉXICO ACTUAL
}

\author{
Jean-François Prud'homme
}

ESTE ARTÍCULO TIENE POR OBJETO proponer una interpretación a un fenómeno difícilmente asible pero tercamente presente en el clima político del fin del gobierno del presidente Calderón: la insatisfacción con la democracia. Me refiero a un estado de ánimo que se percibía en la opinión pública en el año 2012 y que se verificaba en las encuestas aplicadas a la ciudadanía mexicana. No se trataba de sentimientos que ponían en riesgo la supervivencia inmediata de las instituciones políticas democráticas. Tampoco se trataba de actitudes que alimentaban movimientos sociales activos de protesta. Era algo más pernicioso y latente, sin forma clara de expresión, que he decido llamar, por el momento, un "suave desencanto" con la democracia. ${ }^{1}$

El proceso de cambio político que ha vivido México en los últimos veinticinco años ha suscitado grandes expectativas en relación con la democracia. ${ }^{2}$ La elección a la presidencia de la República de un candidato de oposición, Vicente Fox en 2000 incrementó todavía más esas expectativas. Sin embargo, no deja de llamar la atención que, pese a lo cual o quizá precisamente por ello, de acuerdo con las encuestas de opinión publicadas en años recientes, después de dos sexenios de gobierno del Partido Acción Nacional (PAN),

${ }^{1} \mathrm{Si}$ bien la parte final del artículo alude a los primeros meses del gobierno del presidente Peña Nieto y a los retos del establecimiento de una democracia vigorosa, mi interés reside esencialmente en explicar el clima político que prevalecía en los últimos días del sexenio presidencial 2006-2012.

${ }^{2}$ Hago referencia a un ciclo gradual y prolongado de cambios políticos que se inició grosso modo con las elecciones presidenciales de 1988. 
amplios sectores de la población mexicana han expresado un fuerte desencanto a este respecto. En efecto, la encuesta anual de Latinobarómetro sobre el estado de la democracia en América Latina publicada a finales de 2011 ubica a México en los últimos lugares de los países latinoamericanos en cuanto a satisfacción con la democracia.

\section{Cuadro 1}

Porcentaje de satisfacción con la democracia ${ }^{3}$

\begin{tabular}{lcc}
\hline Satisfacción con la democracia & Satisfecho & Insatisfecho \\
\hline Uruguay & 72 & 26 \\
Argentina & 58 & 41 \\
Panamá & 54 & 42 \\
Ecuador & 49 & 49 \\
Venezuela & 45 & 53 \\
Costa Rica & 44 & 51 \\
América Latina & $\mathbf{3 9}$ & $\mathbf{5 7}$ \\
Paraguay & 39 & 59 \\
Nicaragua & 38 & 55 \\
Brasil & 37 & 58 \\
El Salvador & 35 & 63 \\
República Dominicana & 33 & 64 \\
Chile & 32 & 64 \\
Perú & 31 & 64 \\
Honduras & 29 & 68 \\
Bolivia & 28 & 68 \\
Colombia & 27 & 69 \\
Guatemala & 23 & 66 \\
México & $\mathbf{2 3}$ & $\mathbf{7 3}$ \\
\hline
\end{tabular}

Fuente: Latinobarómetro, Informe Latinobarómetro 2011.

${ }^{3}$ La encuesta consiste en 20204 entrevistas que fueron aplicadas entre el 15 de julio y el 16 de agosto de 2011. 
Cuadro 2

Porcentaje que dijo estar satisfecho con la democracia

\begin{tabular}{ccc}
\hline Año & México & América Latina \\
\hline 1995 & 22 & 38 \\
1997 & 45 & 41 \\
2000 & 37 & 36 \\
2002 & 18 & 32 \\
2004 & 17 & 29 \\
2006 & 41 & 38 \\
2008 & 23 & 37 \\
2009 & 28 & 44 \\
2011 & 23 & 39 \\
\hline
\end{tabular}

Fuente: Latinobarómetro, Informe Latinobarómetro 2011.

Según sus resultados, sólo 23\% de los mexicanos se sienten satisfechos con el funcionamiento de la democracia contra un $73 \%$ que se declara insatisfecho (el promedio regional de insatisfacción es de 57\%). México encabeza los países de la región en cuanto al nivel de insatisfacción sobre el funcionamiento de la democracia. De la misma manera, 38\% de los mexicanos declaran no estar convencidos de que "la democracia es el mejor sistema de gobierno", mientras que el promedio regional es de $18 \%$. Según la misma encuesta, 36\% de los mexicanos opinan que "le da lo mismo" que el gobierno sea democrático o autoritario en comparación con una tasa promedio de $18 \%$ para los 17 países latinoamericanos considerados en la encuesta.

Esa tendencia de insatisfacción o indiferencia hacia la democracia se ha duplicado entre 2006 y 2011. Cabe advertir que si examinamos la serie cronológica de las respuestas desde que se aplica la encuesta (1995), se suele observar un repunte en la valoración positiva de la democracia en México durante los años electorales. Sin embargo, los resultados más cercanos a las elecciones presidenciales y legislativas de julio de 2012 -en la misma encuesta pero levantada entre el 31 de mayo y el 30 de junio de 2013- muestran que la tendencia a la insatisfacción con la democracia en la ciudadanía se mantiene. 


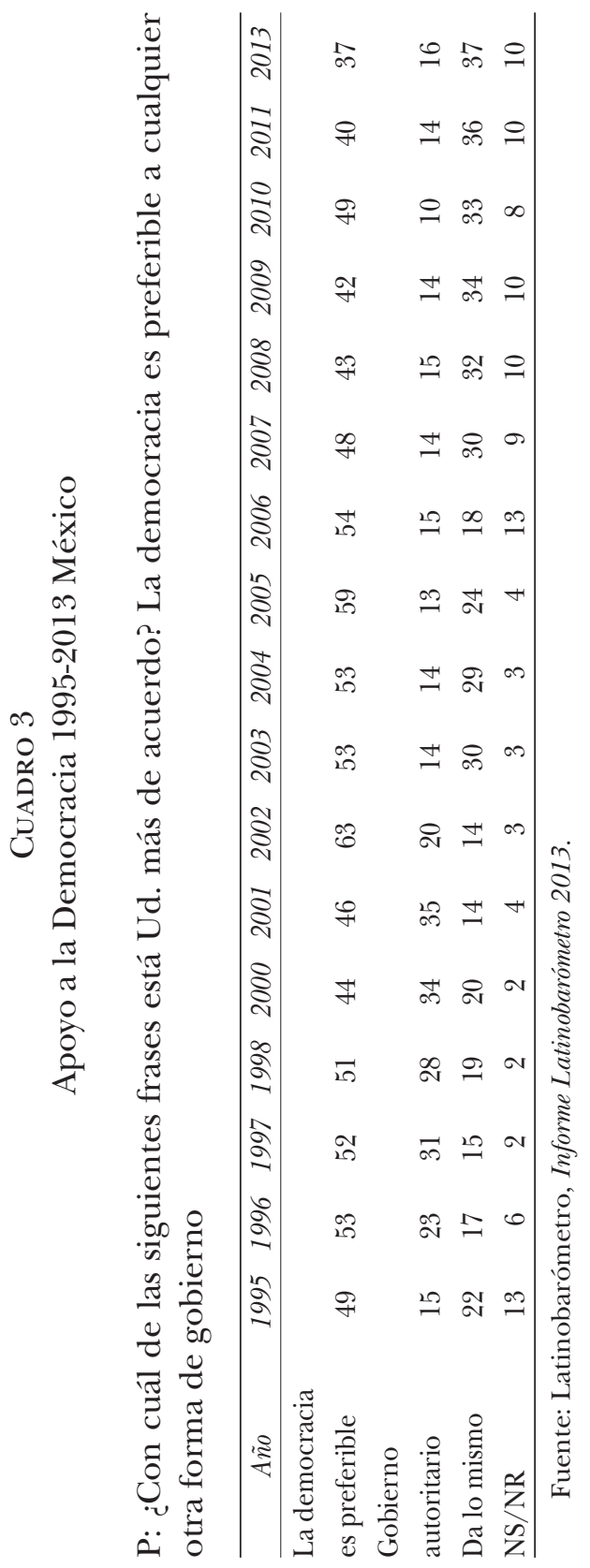


Los datos en el cuadro 3 corresponden con el Informe Latinobarómetro $2013 .{ }^{4} \mathrm{El}$ informe del año 2013, llevado a cabo por la misma organización, refleja una ligera caída en la satisfacción con la democracia en México, pasando de 23\% el número de mexicanos "muy satisfechos" y "más bien satisfechos" en 2011, a 21\% en 2013 (muy por debajo del promedio para América Latina, que se mantuvo en $39 \%$ ). Asimismo, según los datos del Informe Latinobarómetro 2013, 37\% de los mexicanos apoya a la democracia (ante $56 \%$ de latinoamericanos en conjunto), un $16 \%$ prefieren un gobierno autoritario, a $37 \%$ les da lo mismo y $10 \%$ no supo o no respondió. Además, la encuesta de Latinobarómetro no es la única que da cuenta de ese tipo de valoración de la democracia por parte de ciudadanos mexicanos. En efecto, la Encuesta Nacional de Cultura Política y Prácticas Ciudadanas 2012, publicada por la Secretaría de Gobernación, muestra que más de $51 \%$ de los encuestados manifiestan estar "poco o nada satisfecho con la democracia".

\section{Cuadro 4}

Porcentaje de satisfacción en México, 2001-2012

\begin{tabular}{lrrrrr}
\hline & 2001 & 2003 & 2005 & 2008 & 2012 \\
\hline Muy satisfecho & 6.07 & 3.82 & 3.83 & 6.64 & 6.00 \\
Satisfecho/Algo Satisfecho & 27.18 & 19.85 & 21.89 & 27.72 & 24.19 \\
Poco o nada satisfecho & 54.55 & 58.67 & 46.23 & 51.63 & 51.07 \\
\hline
\end{tabular}

Fuente: Elaboración propia con datos de la Encuesta Nacional de Cultura Politica y Prácticas Ciudadanas de 2001 a 2012.

A reserva de estudiar más a fondo esos resultados, la intuición nos dice que corresponden a un cierto "estado de ánimo" que prevalece en el país, un Zeitgeist, como se diría en alemán. Es una situación que no deja de sorprender si la contrastamos con la intensidad de los cambios que han marcado el cambio de un régimen autoritario

${ }^{4}$ Las entrevistas que componen el estudio Latinobarómetro fueron aplicadas entre el 31 de mayo y el 30 de junio 2013, esto es en fechas anteriores al término del periodo del Ejecutivo Federal. 
a uno democrático en los últimos veinticinco años. Es cierto que es difícil distinguir entre la expresión de descontento hacia los gobiernos en turno y la insatisfacción frente al sistema político democrático en su conjunto, pues la relativa juventud del régimen democrático hace que los ciudadanos tiendan a asociar, en sus evaluaciones, el desempeño de los distintos gobiernos al funcionamiento de la democracia en general. El propósito de este capítulo es establecer algunas pistas para reflexionar sobre ese "suave desencanto" con la democracia que parece haberse establecido en el país.

Hablar de un concepto tan amplio y rico como es el de la democracia constituye un reto en sí y más aún cuando se trata de evaluar la naturaleza y la calidad de la vida democrática en el México de hoy. Una de las dificultades que plantea este tema es el hecho de que, además de su amplitud, el concepto de democracia es una noción dinámica, dado que siempre es posible ser más democrático o mejorar la calidad de la vida democrática. Por otra parte, evaluar el estado actual de la democracia mexicana se torna complejo ante la diversidad y complejidad de las variables asociadas a la calidad de la vida democrática. Existe también el riesgo de caer en la trampa del particularismo y hacer de problemas universales de los sistemas políticos democráticos enfermedades exclusivas del sistema político considerado.

Trato de ubicar mi reflexión fuera de la tradición de estudios sobre la "transición" o la "consolidación" democráticas, si bien estoy consciente de que muchos de esos estudios tratan problemas similares al que estoy abordando en este texto. Pienso en particular en los estudios comparados de Hans-Jürgen Puhle sobre los problemas de consolidación democrática y su interesante concepto de "democracias defectuosas". Hay por lo menos tres dimensiones de su reflexión que llaman mi atención y comparto: 1) la necesidad de tomar en consideración los atributos propios a la democracia liberal como el estado de derecho y el respeto a los derechos humanos en la evaluación de las poliarquías; 2) la posibilidad de que las democracias de "baja intensidad" perduren a pesar de tener un déficit de legitimidad; 3) la importancia de fortalecer el estado democrático (lo que él llama 
"stateness"). ${ }^{5}$ Sin embargo, tengo dificultades con el adjetivo "defectuoso" asociado a la definición de "democracias defectuosas" en la medida en que nos remite a un modelo normativo de democracia sin dotarnos de los instrumentos analíticos que explican el carácter defectuoso del sistema.

De manera similar, pero desde el lado autoritario de la frontera entre autoritarismo y democracia, Levitsky y Way se refieren a regímenes híbridos que califican de "autoritarismo competitivo". ${ }^{6} \mathrm{Si}$ bien parecen aludir a problemas que se aparentan a los que interesan aquí, los autores mismos hacen hincapié en que el concepto no se aplica al caso de México post-1997-2000, dado que el país habría logrado transitar hacia la categoría de régimen democrático.

Mi interés reside más bien en tratar de explicar cómo las condiciones propias al funcionamiento del sistema político democrático mexicano pueden producir resultados que contribuyen a debilitar la confianza o las expectativas que la ciudadanía depositó en él.

Este artículo está organizado en tres partes. En la primera analizo la naturaleza del cambio político o de lo que suele llamarse la "transición democrática" y trato de mostrar cómo algunas de sus virtudes se han transformado en deficiencias para la consolidación de una institucionalidad democrática. Luego me refiero a una serie de dimensiones que están asociadas a la calidad de la vida democrática. Finalmente presento una breve reflexión sobre el significado del retorno del Partido Revolucionario Institucional al gobierno en ese contexto.

\section{LA NATURALEZA DEL CAMBio}

Durante los últimos veinticinco años, los cambios que ha experimentado el sistema político mexicano han sido profundos. Se ha pasado de un régimen autoritario caracterizado por el predominio

${ }^{5}$ H.-J. Puhle, "Problemas de consolidación democrática y democracias defectuosas", en W. Bernecker (comp.), Transición democrática y anomia social en perspectiva comparada, México, DAAD-unAm-El Colegio de México, 2004, pp. 15-47.

${ }^{6}$ S. Levitsky y L. S. Way, Competitive Authoritarianism: Hybrid Regimes after the Cold War, Cambridge, Cambridge University Press, 2010. 
de un solo partido político a un régimen democrático. El cambio ha sido el resultado de una combinación de movilizaciones sociales y del incremento de la competencia entre partidos políticos reconocidos. Llaman la atención el carácter gradual de esa transformación, su ubicación en el marco constitucional establecido, la ausencia de ruptura brusca con el pasado y la persistencia de la mayoría de los actores políticos del antiguo régimen, algunos de ellos debilitados pero otros esenciales al funcionamiento del nuevo orden político.

En el centro del amplio proceso de reformas, la transformación de la institucionalidad electoral y de sus reglas de competencia ha ocupado un lugar esencial. Más particularmente, el periodo que se extiende de 1989 a 1996 ha sido marcado por un intenso ciclo de reformas electorales que reprodujo un ciclo de: elecciones-protestas-reformas-elecciones-protestas-reformas-reformas (insurrección zapatista)-elecciones-reformas. Este ciclo fue dominado por las negociaciones entre los tres principales partidos que gozaban de representación en el Congreso, el Partido Revolucionario Institucional (PRI), el Partido de la Revolución Democrática (PRD) y el Partido Acción Nacional (PAN). Y durante diez años la nueva institucionalidad electoral logró producir un nivel de confianza suficientemente aceptable entre adversarios para canalizar las impugnaciones electorales por la vía institucional. ${ }^{7}$

Pero sobre todo, ese ciclo de reformas logró generar un sistema político más plural en su representatividad, más competitivo en el proceso de elección de sus autoridades y representantes, más confiable en la organización y supervisión de sus elecciones y, probablemente, más equitativo en la participación en las contiendas electorales. Esa transformación en el proceso de reclutamiento de los representantes políticos y los gobernantes tuvo por lo menos dos efectos importantes sobre el funcionamiento del sistema político en su conjunto: 1) contribuyó a la separación efectiva de los poderes ejecutivo-legislativo y, luego, judicial; 2) y coadyuvó a la

${ }^{7}$ Para tener una visión completa y precisa del periodo de transformaciones del sistema político al cual hago referencia, véase S. Loaeza y J. F. Prud'homme (coords.), Instituciones y procesos políticos. Los grandes problemas de México, México, El Colegio de México, 2010. 
activación del sistema federal con el acceso a los distintos niveles de gobierno de gobernantes de distinto signo político.

A la vez, se ha instituido una serie de órganos autónomos encargados de proteger ciertos derechos y de regular la actividad en ciertos ámbitos de la actividad pública. Esas entidades van desde el banco central a las distintas comisiones que regulan actividades económicas particulares, pasando los distintos organismos que protegen los derechos humanos, supervisan las elecciones y garantizan el acceso a la información. ${ }^{8}$

En estos veinticinco años, la sociedad mexicana ha ganado más libertad en cuanto a la expresión de ideas y opiniones, tanto en los medios de comunicación en general como en el espacio público. Ese incremento en la libertad de expresión es también el reflejo de una mayor tolerancia hacia la diversidad.

Es importante subrayar esas características, por más que puedan ser objeto de diferentes apreciaciones en cuanto a la intensidad del cambio democrático que vivió el país. Pues resulta fundamental tener en mente el trayecto que ha recorrido el sistema político mexicano en estos últimos veinticinco años para, por una parte, evaluar correctamente el estado actual de la democracia en el país y, por la otra, poder apreciar cómo dicho Estado y algunas de sus deficiencias están estrechamente asociados con la naturaleza del proceso de cambio en México.

Entre las características del proceso cabe resaltar otra vez su naturaleza gradual. En efecto, no ha sido un cambio súbito o espectacular y sería difícil identificar un hecho histórico que señale una ruptura profunda en la democratización del país o bien ponerle fecha al cambio de régimen.

El cambio se dio en el marco del orden constitucional e institucional existente. Y sin negar la importancia de las movilizaciones sociales en el proceso y de las transformaciones que han sufrido los valores y prácticas de muchos agentes sociales y políticos, los cambios han sido esencialmente el producto de negociaciones entre actores que ya estaban incorporados al sistema político. Muestra de

${ }^{8}$ M. C. Pardo, "El Estado mexicano: ¿de la intervención a la regulación?”, en Loaeza y Prud'homme (coords.), op. cit., pp. 71-121. 
ello es el papel central que jugaron los grandes partidos -el PAN, el PRI y el PRD- en la negociación de nuevas reglas de competencia electoral y luego el del Congreso en la adopción de reformas democratizadoras. Esa forma de administrar el cambio tiene grandes virtudes, entre ellas la de ofrecer un grado aceptable de estabilidad y civilidad. Pero, a la vez, esas grandes virtudes contribuyen a explicar el "suave" desencanto que expresa la ciudadanía con respecto a las cualidades y bondades de la vida democrática.

Un motivo de desencanto con respecto al funcionamiento de la democracia es su aparente y relativa ineficacia. Si bien sabemos que las cualidades de los sistemas democráticas no se valoran únicamente en términos de sus resultados, esos no dejan de tener un efecto en su evaluación. Desde 1997, el nuevo pluralismo mexicano ha producido lo que los norteamericanos llaman "gobiernos divididos", es decir gobiernos en los cuales el presidente no cuenta con mayoría en el Congreso. Desde una perspectiva estadística, cuando se considera el conjunto de las iniciativas aprobadas por el Congreso esa división no ha tenido un efecto mayor sobre la colaboración legislativa entre fuerzas políticas. Sin embargo, cuando se toman en consideración las grandes reformas juzgadas esenciales (fiscal, sector energético, etc.), la falta de acuerdo entre las fuerzas políticas ha dificultado su adopción o ha propiciado la aprobación de leyes sin grandes efectos en cuanto al desempeño económico, a la seguridad pública o a la consolidación del Estado de derecho. Por dar algunos ejemplos, el paquete de iniciativas en materia fiscal, La nueva hacienda pública distributiva, presentado por Vicente Fox Quesada el 3 de abril de 2001 a la Cámara de Diputados o el paquete de iniciativas de reforma en materia Energética, Propuesta de Reforma Energética, propuesto por el Felipe Calderón Hinojosa siete años después, el 8 de abril de 2008, no han logrado satisfacer los aspectos trascendentales de una política integral en materia fiscal y energética, respectivamente. ${ }^{9}$

${ }^{9}$ Otros ejemplos de iniciativas importantes enviadas por el Ejecutivo Federal durante los sexenios 2000-2006 y 2006-2012 que han sido contestadas por parte de la oposición son las propuestas de reforma en materia a) fiscal: La Reforma Fiscal de Calderón (06/07); b) energética: La Reforma al Sector Eléctrico de Fox (02/07); c) telecomunicaciones: Apertura del sector de telecomunicaciones a la inversión extranjera de 
La fragmentación del poder propia de un mayor pluralismo, la necesidad de crear mayorías electorales y la persistencia de actores sociales del pasado que ocupan un lugar estratégico en los campos de la economía, de la información y de la vida sindical contribuyen también a limitar el horizonte de las reformas y a crear la percepción de una vida democrática profundamente asimétrica. Es otro motivo de desencanto como también lo es la falta de correspondencia entre derechos y prácticas así como el lento proceso de transformación de esas últimas.

De esta manera, después de subrayar a grandes rasgos y de manera positiva la intensidad de los cambios por los cuales ha atravesado el sistema político mexicano en los últimos años, me quedo con una simple observación: “...y sin embargo...”. Y esa observación me conduce a la segunda parte de esta reflexión, en la que examino diversas dimensiones de la vida democrática nacional.

\section{AlgunAS DIMENSIONES DE LA VIDA DEMOCRÁTICA NACIONAL}

\section{Las instituciones: el Estado}

Durante mucho tiempo en el análisis del sistema mexicano moderno, el concepto de Estado ha ocupado un lugar central. Aparecía a la vez como el lugar de cristalización del poder político y como agente del desarrollo. Se le atribuía una autoridad y una capacidad que no tenía ningún otro actor individual o colectivo en la sociedad mexicana. ${ }^{10}$ Ahora, cuando se reconsidera el concepto de Estado se observa que, en la época del régimen autoritario, el Estado mexicano era mucho menos fuerte de lo que se pensaba: su poder derivaba de la ausencia de competencia en los campos

Calderón (10/12); d) políticas: La iniciativa en Materia Electoral de Fox (03/04), La Iniciativa de Reforma Constitucional en Materia de Veto y Reconducción Presupuestal de Fox (04/05) y Las 10 Nuevas Reformas Políticas de Calderón (12/09); e) laboral: La Iniciativa de Reforma Laboral de Fox (10/02).

${ }^{10}$ En el primer caso véase A. Córdova (La revolución y el Estado en México, México, Era, 1989, pp. 268-299) y en el segundo Bizberg ("La crisis del corporativismo en México”, Foro Internacional, vol. 30, núm. 4, 1990, pp. 701-702). 
que ocupaba y, como se ha documentado ampliamente en estudios históricos y antropológicos, de los arreglos informales que permitían el despliegue de la autoridad estatal en el territorio nacional. En el fondo, el "ogro filantrópico" era mucho más débil de lo que se creía, lo que puede ilustrarse con dos ejemplos: la situación fiscal que muestra una institución con un poder de recaudación muy limitado (el problema no es ahora sino que se remonta lejos en el tiempo) y la necesidad de recurrir a arreglos informales para afirmar su autoridad en el conjunto del territorio nacional, como lo han mostrado los estudios que tratan de la intermediación política (caudillismo, caciquismo y clientelismo). ${ }^{11}$

La debilidad del Estado se hace evidente cuando se incrementa la competencia política y cuando se tambalean los arreglos informales del régimen autoritario, quedando entonces arreglos formales con una eficacia reducida. Por ejemplo, cuando se desmantelaron los mecanismos informales en que se apoyaba el hiperpresidencialismo mexicano (el control del presidente en turno sobre el conjunto de la clase política nacional), nos quedamos con una institución presidencial con facultades formales muy limitadas y con dificultades para establecer una colaboración virtuosa con el poder legislativo, por lo menos en lo que se refiere a reformas juzgadas esenciales para hacer frente a los grandes problemas nacionales. ${ }^{12}$

Esa relativa debilidad del Estado afecta directamente su capacidad de regulación, la cual es fundamental para todo sistema democrático, así como para su desempeño. En su conocido trabajo sobre modelos de democracia, Arend Lijphart utiliza dos dimensiones para medir el desempeño de los gobiernos democráticos: la

${ }^{11}$ Guillermo de la Peña documentó de manera anticipada esa debilidad del Estado mexicano posrevolucionario en un texto brillante sobre la intermediación política en México ("Poder local, poder regional: perspectivas socio-antropológicas”, en J. Padua y A. Vanneph, Poder local, poder regional, México, El Colegio de México-cemcA, 1988, pp. 41-46).

12 Sobre el hiperpresidencialismo mexicano y la "colonización" de los poderes legislativos y judiciales por el poder ejecutivo, véase M. A. Casar, "ExecutiveLegislative Relations: Continuity or Change?”, en A. Selee y J. Peschard (eds.), Mexico's Democratic Challenges: Politics, Government and Society, Washington y Stanford, Woodrow Wilson Center Press-Stanford University Press, 2010, pp. 117-134. 
gestión macroeconómica y el control de la violencia, ambas dimensiones asociadas a la justificación de la existencia del Estado en la argumentación clásica de Hobbes. ${ }^{13}$ Sin reproducir directamente los índices utilizados por Lijphart, resulta revelador examinar algunos indicadores asociados a esas dimensiones para medir la capacidad del Estado democrático en México.

En la primera dimensión, la que está asociada a la capacidad de gestión macroeconómica, vale la pena tomar en consideración dos indicadores de la capacidad estatal. El primero alude a la recaudación fiscal, lo que en el lenguaje de los estudios sobre modernización política se llama la función de extracción del sistema político. Históricamente, el Estado mexicano ha tenido una muy baja capacidad de recaudación fiscal. Los ingresos tributarios del gobierno se han ubicado constantemente alrededor de $10 \%$ del PIB, lo que ubica a México en el último o penúltimo lugar de los países latinoamericanos en la materia. Esa baja capacidad recaudatoria ha sido compensada tradicionalmente por los ingresos directos de la exportación de petróleo que cuentan por una parte sustancial de la hacienda pública. De ahí, la importancia de las discusiones en torno a una reforma fiscal que permita incrementar la capacidad recaudatoria del Estado. Como lo muestra el cuadro 5, la instauración de un régimen democrático no ha permitido todavía solucionar ese problema.

La tasa de crecimiento económico es otro indicador del desempeño de los sistemas políticos. El PIB nacional había crecido a una tasa promedio anual de $3 \%$ entre 1950 y 1981; esa tasa promedio bajó a $0.5 \%$ entre 1981 y 2008. ${ }^{14} \mathrm{Si}$ bien se puede argumentar que la tendencia a un bajo crecimiento económico caracteriza a un ciclo económico que antecede a la instauración de la democracia, no deja de llamar la atención que el inicio de un nuevo régimen no haya logrado revertir esa tendencia (cuadro 6).

${ }^{13}$ Arend Lijphart, Patterns of Democratic Government: Forms and Performance in the Thirty-Six Countries, New Haven y Londres, Yale University Press, 1999, pp. 258-274.

${ }^{14}$ G. Esquivel, "De la inestabilidad macroeconómica al estancamiento estabilizador: el papel del diseño y la conducción de la política económica”, en N. Lustig (coord.), Los grandes problemas de México, IX: Crecimiento económico y equidad, México, El Colegio de México, 2010, p. 38. 
Cuadro 5

Ingresos tributarios, 1994-2012a

\begin{tabular}{cc}
\hline Año & Porcentaje del PIB \\
\hline 1994 & 11.3 \\
1995 & 9.1 \\
1996 & 8.9 \\
1997 & 9.8 \\
1998 & 10.5 \\
1999 & 11.4 \\
2000 & 10.6 \\
2001 & 11.3 \\
2002 & 11.6 \\
2003 & 11.1 \\
2004 & 9.0 \\
2005 & 8.8 \\
2006 & 8.6 \\
2007 & 8.9 \\
2008 & 8.2 \\
2009 & 9.5 \\
2010 & 9.6 \\
2011 & 9.0 \\
2012 & 8.5 \\
\hline
\end{tabular}

Fuente: Sistema de Administración Tributaria, Informe Tributario y de Gestión de 2005 y 2013.

Desde luego, la tasa de recaudación fiscal o la tasa de crecimiento del pIB no son los únicos indicadores que dan cuenta del desempeño económico de un gobierno y de la capacidad de un

a Los ingresos tributarios se refieren a todos los impuestos que obtiene la Federación y que están vigentes en la Ley de Ingresos aprobada para un determinado ejercicio fiscal aprobado, por ejemplo, el Impuesto al Valor Agregado, el Impuesto a los Rendimientos Petroleros y otros más. No obstante, en los datos no se incluyen todos los ingresos petroleros del sector público, como los ingresos propios de Petróleos Mexicanos. Secretaría de Hacienda y Crédito Público, "Balance Fiscal en México. Definición y Metodología”, 2013, p. 15. 
Estado en materia de gestión macroeconómica. Otros indicadores tienen que ser tomados en consideración, como por ejemplo el control de la inflación, la acumulación de reservas, etc. En esos campos, los gobiernos democráticos mexicanos han tenido un buen desempeño. Sin embargo, el desempeño en materia de recaudación fiscal y crecimiento económico evidencia debilidades del Estado democrático o sus dificultades para revertir tendencias establecidas en las últimas tres décadas. Veremos más adelante cómo esas debilidades se reflejan también en la distribución del ingreso. De ahí, se puede explicar que para segmentos importantes de la población no haya diferencias entre la democracia y otras formas de gobierno.

Cuadro 6

Crecimiento económico, 1994-2011

\begin{tabular}{cc}
\hline Año & Porcentaje de crecimiento del PIB \\
\hline 1994 & 4.46 \\
1995 & -6.22 \\
1996 & 5.14 \\
1997 & 6.78 \\
1998 & 4.91 \\
1999 & 3.87 \\
2000 & 6.60 \\
2001 & -0.16 \\
2002 & 0.83 \\
2003 & 1.35 \\
2004 & 4.05 \\
2005 & 3.21 \\
2006 & 5.15 \\
2007 & 3.26 \\
2008 & 1.19 \\
2009 & -5.95 \\
2010 & 5.53 \\
2011 & 3.91 \\
\hline
\end{tabular}

Fuente: Datos obtenidos del Banco Mundial, 2012. 
Cuadro 7

Total de homicidios por año, 1990-2011

\begin{tabular}{cc}
\hline Año & Defunciones por homicidio \\
\hline 1990 & 28986 \\
1991 & 15128 \\
1992 & 16594 \\
1993 & 16040 \\
1994 & 15839 \\
1995 & 15612 \\
1996 & 14505 \\
1997 & 13552 \\
1998 & 13656 \\
1999 & 12249 \\
2000 & 10737 \\
2001 & 10285 \\
2002 & 10088 \\
2003 & 10087 \\
2004 & 9329 \\
2005 & 9921 \\
2006 & 10452 \\
2007 & 8867 \\
2008 & 14006 \\
2009 & 19803 \\
2010 & 25757 \\
2011 & 27213 \\
\hline
\end{tabular}

Fuente: Datos obtenidos del Instituto Nacional de Estadística y Geografía, "Defunciones por homicidio" de 19902011.

La otra dimensión que utiliza Lijphart para evaluar el desempeño de los gobiernos democráticos -y que tomo la libertad de extender a la evaluación de la capacidad del Estado- es el control sobre la violencia. Durante la primera década del siglo xxi, la violencia asociada a la lucha contra el narcotráfico ha crecido de manera importante en México tanto en términos numéricos como en la crueldad y visibilidad de su ejercicio. Es un hecho de notoriedad pública, como lo es también la capacidad diferenciada del Estado 
de asentar su autoridad en el conjunto del territorio nacional. Según Fernando Escalante, si examinamos la evolución en números absolutos del total de homicidios en el país, podemos notar una disminución apreciable durante la década de 1995 a 2005. Sin embargo, en el periodo 2008-2011, hay un repunte impresionante de ese tipo de crimen (cuadro 7).

El problema del control de la violencia no está solamente asociado al incremento de los actos delictivos, sino también a la eficacia del sistema judicial para procesarlos. Un estudio del Centro de Investigación para el Desarrollo muestra que no solamente la tasa de crímenes reportados de toda naturaleza es muy baja, sino que la tasa de crímenes investigados alcanza apenas $9 \%$ de los crímenes reportados en 2010 (cuadro 8). Si tomamos en consideración ahora el porcentaje de crímenes investigados que fueron objeto de sentencia en 2010, la tasa baja a 7\% (cuadro 9). Aquí también, el desempeño de los gobiernos democráticos muestra una baja capacidad estatal en cuanto al control de la violencia.

CuAdro 8

Incidencia criminal vs. crímenes reportados, 2000-2010

\begin{tabular}{lccc}
\hline & $\begin{array}{c}\text { Incidencia criminal } \\
\text { (por 100000 habitantes)* }\end{array}$ & $\begin{array}{c}\text { Crímenes reportados } \\
\text { (por 100000 habitantes) }\end{array}$ & $\begin{array}{c}\text { Porcentaje de } \\
\text { crimenes reportados }\end{array}$ \\
\hline 2000 & 306387 & 44705 & $14.6 \%$ \\
2001 & 323888 & 46764 & $14.4 \%$ \\
2002 & 319290 & 45536 & $14.3 \%$ \\
2003 & 312459 & 44157 & $14.1 \%$ \\
2004 & 324524 & 43392 & $13.4 \%$ \\
2005 & 311363 & 45085 & $14.5 \%$ \\
2006 & 310663 & 47023 & $15.1 \%$ \\
2007 & 339505 & 50211 & $14.8 \%$ \\
2008 & 330641 & 50892 & $15.4 \%$ \\
2009 & 325967 & 50531 & $15.5 \%$ \\
2010 & 312284 & 49186 & $15.8 \%$ \\
\hline
\end{tabular}

*La incidencia criminal es la suma de los crímenes reportados y los crímenes no reportados.

Fuente: Centro de Investigación para el Desarrollo, A. C., "Red Numbers of the Criminal Justice System in Mexico”, 2011. 
Cuadro 9

Eficiencia judicial, 1997-2010

\begin{tabular}{ccc}
\hline Año & $\begin{array}{c}\text { Crimenes investigados } \\
\text { Crimenes reportados } \\
\text { con sentencia }\end{array}$ \\
\hline 1997 & $10 \%$ & $8 \%$ \\
1998 & $11 \%$ & $8 \%$ \\
1999 & $11 \%$ & $9 \%$ \\
2000 & $12 \%$ & $9 \%$ \\
2001 & $11 \%$ & $9 \%$ \\
2002 & $12 \%$ & $9 \%$ \\
2003 & $12 \%$ & $9 \%$ \\
2004 & $13 \%$ & $10 \%$ \\
2005 & $13 \%$ & $10 \%$ \\
2006 & $12 \%$ & $9 \%$ \\
2007 & $11 \%$ & $9 \%$ \\
2008 & $11 \%$ & $8 \%$ \\
2009 & $10 \%$ & $8 \%$ \\
2010 & $9 \%$ & $7 \%$ \\
\hline
\end{tabular}

Fuente: Centro de Investigación para el Desarrollo, A. C., "Red Numbers of the Criminal Justice System in Mexico", 2011.

Frente a esta situación de baja capacidad estatal, se han expresado voces nostálgicas que llaman a la recuperación de un orden autoritario perdido. Desde luego, no es mi intención llamar a la reconstitución de un Estado de antiguo régimen. Tampoco busco asimilar esa baja capacidad estatal a la existencia de un "Estado fallido". No es el caso mexicano.

Sin embargo, Hans Jürgen Puhle tiene razón cuando afirma con otros, como Linz y Stepan, que las democracias sólidas requieren de un cierto grado de "stateness" y sobre todo que el componente liberal de la democracia liberal es esencial al robustecimiento del Estado de derecho. ${ }^{15}$

De ahí, el reto que se plantea en México de construir un Estado democrático fuerte, es decir un Estado de derecho fuerte. No se trata de regresar nostálgicamente a una concepción autoritaria

15 Puhle, art. cit. 
del Estado, sino más bien de consolidar un Estado con capacidad de regulación que permita hacer valer los derechos de los ciudadanos. Paradójicamente, el carácter gradual y negociado de la larga transición mexicana ha dejado inacabada la tarea de consolidación de las instituciones. Da la impresión de que en ciertas circunstancias los sistemas democráticos tienen dificultades para completar la reforma de sus instituciones y encontrar soluciones a los problemas del momento: la dispersión de las preferencias electorales, la fragmentación de la representación política, la polarización ideológica, los imperativos de la competencia electoral, el predominio de los objetivos a corto plazo y la falta de una cultura de colaboración parecen combinarse en contra de la eficacia política. A la falta de atributos formales que le dan fuerza a la autoridad estatal se agrega la debilidad de los arreglos informales que deberían sustentar la cultura democrática. No es que no exista la conciencia de la necesidad de fortalecer las instituciones estatales o de elaborar políticas que permitan ese fortalecimiento como lo muestra una serie de reformas

\section{Las instituciones: el sistema político}

Otra dimensión que presenta el proceso de cambios se refiere al sistema político nacional, en el cual se observa, como ya lo mencioné, pluralismo, diversificación de la representación política, consolidación de la separación de poderes y dinamización del federalismo.

Por un lado, resulta fascinante observar cómo se reactivó el espíritu de las reglas constitucionales mexicanas, pero, por el otro, parecería que se sigue viviendo un largo periodo de ajuste que no permite todavía consolidar un modelo adecuado de relaciones entre poderes y entre entidades de la federación y gobierno central. La cuestión de la colaboración entre fuerzas políticas opuestas sobre todo cuando se trata de tomar decisiones importantes sigue siendo un problema. La visión de corto plazo marcada por el calendario electoral parece imponerse y dificulta el acuerdo sobre temas de largo alcance. 
Así, el reacomodo entre poderes obliga a inventar procesos estables o predecibles de relación entre ellos, lo que supone un aprendizaje del modelo virtuoso de relaciones entre dichos poderes.

\section{Sistemas electorales y de partidos}

Desde el periodo autoritario cuando se estableció el sistema moderno de partidos y luego, durante el largo proceso de reformas que llevó a la democratización del sistema político, prevaleció una concepción idealizada de los partidos y del sistema de partidos. Funcionaba como un objetivo por alcanzar cuando lo permitiera el grado de madurez de la sociedad. Esa concepción idealizada suponía la existencia de un número limitado de partidos políticos fuertes en un sistema de partidos altamente institucionalizado. Ese modelo guio el espíritu de las reformas electorales. ${ }^{16}$ De hecho, la ley electoral ofrece un alto grado de protección a los partidos establecidos. A pesar del progreso electoral de las pequeñas formaciones políticas en las elecciones de 2009 y 2012, los tres grandes partidos siguen distribuyéndose más de $80 \%$ de los votos.

Esa distribución de las preferencias entre tres grandes partidos, aunada a una fórmula electoral que dificulta la formación de gobiernos mayoritarios, ha provocado la situación de gobierno dividido a la cual hice referencia anteriormente. Esto obliga a formar coaliciones legislativas amplias para la aprobación de las leyes. Es un proceso que ha funcionado para la adopción de muchas leyes secundarias. De hecho, en las legislaturas de 2003-2006 y de 2006-2009 más de 50\% de las iniciativas legislativas del poder ejecutivo fueron aprobadas por todos los partidos políticos. Esa cifra sube a $68 \%$ cuando se trata de iniciativa que tienen su origen en el poder legislativo. ${ }^{17}$ De la misma manera, en las mismas legislaturas 52 y $86 \%$ de las iniciativas con origen en el poder legislativo fueron aprobadas por mayoría en el Congreso.

16 Véase J. F. Prud'homme, "Los partidos políticos", en S. Loaeza y J. F. Prud'homme (coords.), op. cit., pp. 121-158.

${ }^{17}$ M. A. Casar, "Representation and Decision Making in the Mexican Congress”, México, CIDE, Working Paper, núm. 258, 2011, p. 12. 


\section{Cuadro 11}

Número de iniciativas de ley propuestas por el Poder Ejecutivo a la Cámara de Diputados, 1997-2009

\begin{tabular}{ccccc}
\hline Estatus & $\begin{array}{c}\text { Legislatura LVII } \\
(1997-200)\end{array}$ & $\begin{array}{c}\text { Legislatura LVIII } \\
(2000-2003)\end{array}$ & $\begin{array}{c}\text { Legislatura LIX } \\
\text { (2003-2006) }\end{array}$ & $\begin{array}{c}\text { Legislatura LX } \\
\text { (2006-2009) }\end{array}$ \\
\hline Enviadas & 32 & 60 & 44 & 37 \\
Aprobadas & 25 & 47 & 23 & 32 \\
Pendientes & 6 & 12 & 19 & 5 \\
Rechazadas & 1 & 1 & 2 & 0 \\
Tasa de Aprobación & $78 \%$ & $78 \%$ & $52 \%$ & $86 \%$ \\
\hline
\end{tabular}

Fuente: María Amparo Casar, "Representation and Decision Making in the Mexican Congress”, 2011.

A pesar de esa tasa relativamente alta de colaboración entre poderes y entre partidos representados en el Congreso, en la opinión popular predomina la idea de que los partidos no logran cooperar para solucionar los grandes problemas nacionales. Esa opinión se basa en el hecho de que las reformas que son juzgadas necesarias para mejorar la situación económica del país o para solucionar problemas de orden social han sido objeto de vetos poderosos, o, cuando han sido adoptadas, su contenido había sido muy diluido. Me refiero desde luego a reformas en materia fiscal, laboral, antimonopólica, de la educación, del sector energético y de las instituciones políticas. En esos casos, la polarización ideológica entre partidos y el ejercicio de veto por parte de actores sociales y económicos estratégicos han contribuido a bloquear o diluir los intentos de reforma. Es una de las explicaciones al bajo grado de satisfacción de la población en cuanto al funcionamiento y al desempeño de la democracia. Desde luego, queda la pregunta a saber si esa situación se debe a los arreglos institucionales que sustentan el sistema de partidos, al comportamiento de esos mismos partidos o a las divisiones ideológicas por las que atraviesa la sociedad. Lo más probable es que haya un poco de los tres elementos.

Otro efecto de la concepción prevalente de un sistema altamente institucionalizado de partidos fuertes y bien protegidos por la legislación electoral reside en la distancia existente entre los 
partidos y la ciudadanía. Si bien una proporción importante de ellos declara identificarse con un partido político (cerca de $54 \%$ en 2012), estos siguen registrando el marcador más bajo cuando se trata de evaluar la confianza en las instituciones. ${ }^{18}$ Finalmente, habrá que mencionar el hecho de que a pesar de contar con sólidas garantías legales (me refiero al financiamiento, a las condiciones de aparición y consolidación de otras fuerzas políticas, etc.) los partidos se enfrentan frecuentemente a situaciones de crisis interna. Por ejemplo, en el momento de escribir estas líneas los dos principales partidos de oposición el PAN y el PRD se encuentran inmersos en profundas crisis políticas. No es una situación que existe solamente en México, pero no ayuda a mejorar la imagen de los partidos ante el electorado.

\section{La sociedad civil y los grupos de interés}

Como lo documentan diversos estudios, existe un cierto grado de decepción y desencanto con la sociedad civil, basado en que se tenía la idea romántica de una sociedad civil apropiada a un momento de cambio, es decir una sociedad civil movilizada, interesada en los asuntos públicos y portadora de una nueva moral política. ${ }^{19} \mathrm{Si}$ bien la vida asociativa es importante en México, el papel que desempeñan los actores identificado a la sociedad civil había sido sobrevalorado, en particular en lo relativo a su capacidad de movilización permanente y a la naturaleza de sus intereses, los cuales, cabe destacarse, son muy diversos. ${ }^{20} \mathrm{Si}$ bien, en años recientes han surgido movimientos sociales como el Movimiento por la Paz animado por el poeta Javier Sicilia, que defiende los derechos de las víctimas inocentes en la lucha contra el

${ }^{18}$ M. F. Somuano, "Las identidades partidistas de los mexicanos y la elección de 2012”, manuscrito, 2013.

${ }^{19}$ A. Olvera "Las tendencias generales de la sociedad civil en México", en A. Olvera (comp.), Sociedad civil, esfera pública y democratización en México, Xalapa y México, Universidad Veracruzana/FCE, 2003, pp. 42-70.

${ }^{20}$ Somuano, "Las organizaciones civiles: formación y cambio", en S. Loaeza y J. F. Prud'homme (coords.), op. cit., pp. 197-230. 
narcotráfico, o el movimiento \#YoSoy132, que movilizó a los estudiantes durante la campaña electoral de 2012, la realidad que mostró la composición de la sociedad civil fue muy distinta.

De hecho, lo que se ha revelado es el carácter profundamente asimétrico del pluralismo y del universo de los intereses y una cierta debilidad del Estado democrático frente a ciertas corporaciones económicas, mediáticas o sindicales, que ocupan un lugar estratégico en el sistema político y que han logrado posicionarse como esenciales a la formación de mayorías electorales -uno de los elementos vitales de la vida democrática-, o al funcionamiento de la economía o al mantenimiento del orden social. Frente a estos actores, que poseen una gran capacidad de veto, la vulnerabilidad del Estado democrático sale a relucir. En los últimos años se ha acuñado un término en el lenguaje popular mexicano para designar a esos actores: los "poderes fácticos". Por esa expresión poco elegante se designa a los actores sociales que parecen tener una influencia desproporcionada en la toma de decisiones públicas: entre ellos están las grandes corporaciones televisivas y de telecomunicaciones (Televisa, TV Azteca, Telmex), poderosos sindicatos (Sindicato Nacional de los Trabajadores de la Educación, Sindicato Nacional de Trabajadores Petroleros) y grandes grupos empresariales. A muchos de ellos, se ha atribuido una influencia desproporcionada en el bloqueo de las reformas juzgadas esenciales para solucionar grandes problemas nacionales, por lo menos, una gran capacidad de presión sobre los poderes legalmente constituidos para que se hagan reformas que les beneficien a ellos. Esa situación acentúa el carácter asimétrico del nuevo pluralismo mexicano. Desde luego, hablar de grupos de la sociedad civil de manera más comprensiva nos obligaría a mencionar el tema de la delincuencia organizada que en muchas regiones del país tiene una visibilidad ineludible. Sin embargo, es tema que rebasa mi campo de conocimiento y mis capacidades analíticas.

\section{Desigualdad y ciudadanía}

A esas dificultades se deben agregar los obstáculos que impiden consolidar el sistema democrático en sociedades que presentan un 
alto nivel de desigualdad económica y social, es decir, el impacto que esto ejerce sobre la formación de una ciudadanía plena. Entre los resultados mitigados de la democracia en México está la dificultad de reducir la desigualdad entre grupos sociales; de hecho, según datos del Coneval se ha incrementado la tasa de personas en situación de pobreza desde 2006. Si bien se observaba una tendencia descendiente desde el año 2000 en materia de pobreza, esa tendencia se ha revertido.

CuAdro 12

Porcentaje de personas en pobreza, 1992-2010

\begin{tabular}{cccc}
\hline Año & $\begin{array}{c}\text { Pobreza de } \\
\text { patrimonio }\end{array}$ & $\begin{array}{c}\text { Pobreza de } \\
\text { capacidades }\end{array}$ & $\begin{array}{c}\text { Pobreza } \\
\text { alimentaria }\end{array}$ \\
\hline 1992 & 53.1 & 29.7 & 21.4 \\
1994 & 54.4 & 30 & 21.2 \\
1996 & 69 & 46.9 & 37.4 \\
1998 & 63.7 & 41.7 & 33.3 \\
2000 & 53.6 & 31.8 & 24.1 \\
2002 & 50 & 26.9 & 20 \\
2004 & 47.2 & 24.7 & 17.4 \\
2005 & 47 & 24.7 & 18.2 \\
2006 & 42.7 & 20.7 & 13.8 \\
2008 & 47.7 & 25.3 & 18.4 \\
2010 & 51.3 & 26.7 & 18.8 \\
\hline
\end{tabular}

Fuente: Estimaciones del Consejo Nacional de Evaluación de la Política de Desarrollo Social con base en las Encuestas Nacionales de Ingresos y Gastos de los Hogares de 1992 a 2010.

En cuanto a la desigualdad social, se puede observar que el coeficiente de GINI ubica a México entre Venezuela y Brasil, y que durante la primera década del siglo xxi no se han realizado progresos importantes en la materia.

Tanto la tasa de pobreza como el nivel de desigualdad social son indicadores del desempeño de los gobiernos (o del Estado). Sin embargo, sabemos que los sistemas democráticos pueden sobrevivir con altos niveles de desigualdad social. No hay una correlación 
directa entre igualdad o prosperidad y democracia. Pero tener una ciudadanía diferenciada no ofrece una base sólida para el desarrollo de la vida democrática. Si bien se han logrado avances en materia de derechos ciudadanos en los últimos veinte años, la persistencia de fuertes desigualdades favorece el ejercicio diferenciado de dichos derechos. Además, la situación de violencia asociada a la lucha al narcotráfico ha provocado lo que en el lenguaje cotidiano en México se llama "daños colaterales". Los informes de derechos humanos llaman cada vez más la atención sobre los periodistas asesinados y las víctimas inocentes que quedaron atrapadas entre dos fuegos. Esa situación llevó a la formación de un Movimiento por la Paz en defensa de los derechos de las víctimas inocentes del combate contra el narcotráfico.

Cuadro 13

Coeficiente de Gini, 2002-201121

\begin{tabular}{llllllllll}
\hline & 2002 & 2004 & 2005 & 2006 & 2007 & 2008 & 2009 & 2010 & 2011 \\
\hline Brasil & 0.634 & 0.612 & 0.613 & 0.605 & 0.59 & 0.594 & 0.576 & & 0.559 \\
México & 0.514 & 0.516 & 0.528 & 0.506 & & 0.515 & & 0.481 & \\
Venezuela & 0.5 & 0.47 & 0.49 & 0.447 & 0.427 & 0.412 & 0.416 & 0.394 & 0.397 \\
\hline
\end{tabular}

Fuente: Elaboración propia con datos de la Comisión Económica para América Latina y el Caribe.

La cultura política, los valores y las prácticas

$\mathrm{Al}$ establecer una evaluación del cambio en México, he resaltado la presencia de una sociedad más diversa, más libre y más tolerante, aun si se observa una diferenciación en la evolución de los valores y prácticas entre diferentes espacios públicos y distintas partes del territorio nacional. Persisten diferencias importantes a lo largo del territorio nacional. Coexisten enclaves autoritarios

${ }^{21}$ El Coeficiente de Gini es un índice para medir la distribución del ingreso. Los valores que toma del Coeficiente están en un rango de $(0,1)$, donde cero es la equidad absoluta y uno es la inequidad absoluta. CEPALSTAT, "Índice de concentración de Gini”, ficha técnica, 2013. 
donde prevalecen valores y prácticas del pasado con espacios mucho más avanzados en cuanto a derechos y comportamientos sociales (pienso en el Distrito Federal, por ejemplo). Frecuentemente, las instituciones políticas acentúan esas diferencias. Una de las características de la reactivación del federalismo mexicano consiste en mostrar la heterogeneidad nacional en cuanto al respeto a los derechos y en cuanto a la responsabilidad de los gobiernos: un ejemplo frecuentemente mencionado es el de la transparencia y de la rendición de cuentas. Si bien se nota un avance importante en las instituciones del sistema político federal, la situación es distinta en el nivel de los estados, donde frecuentemente el gobernador tiene pocos contrapesos. Por lo tanto, ciertos valores y prácticas del pasado como el clientelismo, por ejemplo, siguen teniendo un fuerte peso en muchas áreas de la vida democrática del país. Si bien la democracia puede acomodarse con elementos asociados a la continuidad del pasado autoritario, la persistencia de esos elementos tiende a debilitar la calidad de la vida democrática. Esa situación tiende, entre otras cosas, a dificultar el desarrollo de una concepción compartida del dominio público.

Cabe aquí señalar que muchas transiciones se caracterizan por un cierto fetichismo con respecto a las normas. Es decir, se considera que basta con promulgar y acumular normas reformadoras para cambiar los comportamientos. La experiencia nos muestra que no es así. De ahí, la importancia de modificar los valores y las prácticas. Es una tarea de mediana y largo plazo.

Así es que nos encontramos en una situación paradójica. El propio funcionamiento del sistema democrático dificulta la profundización de reformas democráticas y contribuye a aumentar un "suave desencanto" con la misma democracia. Ese desencanto se expresa tanto por una sensación de ineficacia del sistema político actual en cuanto a sus resultados generales y mecanismos de toma de decisiones, así como por una decepción en cuanto al ritmo de integración de derechos asociados a valores democráticos en la vida pública nacional (cambio de prácticas políticas). Es en este contexto que se debe entender el regreso del PRI en el gobierno del país. 


\section{El REGRESO DEL PRI}

En efecto, el 1 de julio de 2012, Enrique Peña Nieto, candidato de la coalición Compromiso por México formada por el PRI y el Partido Verde Ecologista de México (PVEM), ganó la elección presidencial con $38.2 \%$ de los votos. Asumió el poder el 1 de diciembre de 2012 después de doce años de gobierno del Partido Acción Nacional (PAN).

\section{Cuadro 14}

Porcentaje de votación en elección presidencial, 1976-2012

\begin{tabular}{lccccccc}
\hline & \multicolumn{7}{c}{ Elecciones } \\
& 1976 & 1982 & 1988 & 1994 & 2000 & 2006 & 2012 \\
\hline PRI & 86.37 & 68.43 & 50.7 & 48.69 & 36.11 & 22.23 & 38.21 \\
PAN & & 15.68 & 16.79 & 25.92 & 42.52 & 35.89 & 25.41 \\
PRD & & & & 16.59 & 16.64 & 35.33 & 31.59 \\
Otros & 7.11 & 9.77 & 32.48 & 6.37 & 2.55 & 4.63 & 2.29 \\
Total & 93.48 & 93.88 & 99.97 & 97.57 & 97.82 & 98.08 & 97.5 \\
\hline
\end{tabular}

Fuente: Elaboración propia con datos del Instituto Federal Electoral y la Political Database of the Americas.

Si bien la victoria del viejo partido hegemónico suscitó muchas interrogaciones en cuanto a su significado real, hablar de un "retorno" de ese partido plantea ciertas dificultades, porque en realidad durante los años en que no gobernó el país ese partido siguió teniendo una presencia ineludible en la vida política nacional. Hemos visto en las secciones anteriores cómo el PRI fue un actor importante de las sucesivas negociaciones que llevaron al cambio de régimen en las décadas de 1980 y 1990. Aún en la primera década del siglo XXI, con la excepción del periodo 2006-2009, el PRI mantuvo una sustantiva representación en la Cámara de Diputados: de hecho, en los periodos 2000-2003 (208), 2003-2006 (222) y 20092012 (241) su bancada parlamentaria fue la más numerosa. De la misma manera, durante ese mismo periodo nunca gobernó menos de 17 de los 32 estados de la República. En nueve de esos estados nunca dejó de ser gobierno, es decir que nunca hubo alternancia 
en el poder. Por lo tanto, en cuanto a la representación política, el PRI se mantuvo como un actor de peso en la vida política nacional.

Durante todo ese tiempo, siguió siendo el partido con más presencia en el conjunto del territorio nacional, como lo atestigua el hecho de que las competencias electorales en los estados solían darse entre binomios PRI-PAN O PRI-PRD, lo que llevó a hablar de un sistema bipartidista de tres partidos, en el cual el PRI era el eje de las contiendas. ${ }^{22}$ Por ello, el aparato electoral de ese partido siguió siendo el más poderoso del país.

Pero la victoria del PRI se puede explicar sobre todo porque, a raíz de sus derrotas electorales, aprendió a competir electoralmente (aun si algunos dudan de sus métodos de movilización de los votos), porque logró recrear la cohesión de su dirigencia nacional ahora unida en torno a un candidato popular y, más que nada, porque supo sacar provecho de la insatisfacción del electorado después de doce años de gobierno del Partido Acción Nacional. Paradójicamente, el partido que está asociado históricamente al régimen autoritario supo sacar provecho del juego democrático y presentarse como una mejor opción de gobierno que el partido de oposición de izquierda, el PRD.

Ahora, las preguntas que interesan a los analistas en esta situación son las siguientes: ¿se trata de un nuevo PRI? y ¿esa victoria electoral significa un regreso al autoritarismo?

La respuesta a la primera pregunta es ambigua. No hay ningún acontecimiento antes de las elecciones de 2012 que nos permita hablar de una refundación de ese partido político, es decir que no hubo ningún congreso en el cual se proclamara la adhesión a nuevos principios y valores democráticos (probablemente porque ese partido siempre se consideró a sí mismo como democrático). Al mismo tiempo, hay que reconocer que desde mediados de la década de 1990 el PRI acató los principios elementales de la competencia electoral democrática. Además, para responder

${ }^{22}$ Desde luego, hay excepciones notables, como el caso del Distrito Federal donde la competencia ha sido PRD-PAN, ya que en esa entidad el PRI perdió su estructura y su voto duro. 
de manera más directa a la pregunta acerca del carácter novedoso o no del PRI actual, se puede observar que el gabinete del nuevo presidente está constituido por una mezcla de viejos políticos de ese partido con una nueva generación de jóvenes políticos cuyo apego a los ritos y prácticas del pasado ignoramos.

De todas maneras, el argumento más poderoso para responder a la pregunta reside no tanto en el PRI, en sus convicciones y prácticas, sino más bien en los cambios que se han efectuado en el sistema político en los últimos años. El PRI que está en el gobierno en el año 2012 se encuentra funcionando en un entorno institucional en el cual existe una separación real de los poderes (con una presidencia menos poderosa que en el pasado), en el cual el federalismo ha sido reactivado y en donde existe una serie de órganos estatales autónomos que ejercen funciones de regulación y supervisión de la vida pública. Además, se da una competencia política real entre partidos, hay un gran pluralismo en la representación política y una opinión pública más vigorosa. En pocas palabras, el gobierno tiene contrapesos. ${ }^{23}$

Es previsible que la influencia de la vieja cultura política del PRI sobre el estado de la democracia en el país sea puesta a prueba cuando el gobierno se enfrente con problemas asociados a prácticas autoritarias o arbitrarias en el seno de esa misma formación política. Pienso por ejemplo en la actitud que adoptará el gobierno frente a prácticas autoritarias o actos de corrupción o clientelismo de gobernadores $\mathrm{u}$ otros funcionarios electos de ese mismo partido. Es importante recordar que se trata de un partido que reúne a una coalición muy heterogénea de intereses e individuos con valores y prácticas muy distintos, y que en muchas regiones del país sigue practicando la política a la antigua.

Ahora, los primeros meses del gobierno del presidente Enrique Peña Nieto han mostrado un cambio en las prioridades del gobierno y, sobre todo, en la estrategia de comunicación social de

${ }^{23}$ Es un argumento que encontramos en J. Woldenberg, "Mi lectura de las elecciones”, Letras Libres, núm. 165, septiembre de 2012; y en R. Hernández Rodríguez y W. Pansters, "La democracia en México y el regreso del PRI", Foro Internacional, vol. 52, núm. 210, 2012, pp. 755-795. 
los nuevos dirigentes. Se ha promovido tanto en el nivel internacional como en el doméstico una idea del "momento de México" o "the Mexican moment" para retomar la expresión en inglés. Esa estrategia consiste en promover las oportunidades económicas que ofrece el país dejando en el segundo plano el tema de la violencia que caracterizó al sexenio anterior. En cierta medida, la promoción de esa imagen parece estar funcionando por lo menos en cuanto al espíritu que anima a la opinión pública inclusive si la realidad no ha cambiado sustantivamente. Desde luego, ese optimismo aparente nos obliga a cuestionar el origen del "suave desencanto" con la democracia, al que hago referencia en las primeras páginas de este artículo. Muchos analistas políticos podrán argumentar que ese desencanto estaba más asociado a la insatisfacción con el gobierno del presidente Calderón que a problemas estructurales de la nueva democracia mexicana. Sin embargo, muchas acciones del nuevo gobierno y de los principales actores políticos parecen responder a un diagnóstico de dificultades de fondo en el funcionamiento del sistema político.

Resulta difícil contrastar planes de gobierno, buenas intenciones y voluntad de reforma con los problemas estructurales de la nueva democracia evocados en las páginas anteriores. Hay una diferencia de registro importante. Además, la evaluación de las acciones de gobierno obliga a tomar en consideración un ciclo largo de toma de decisiones y aplicación de las políticas. En el caso de México, esto significa tomar en consideración para las reformas fundamentales la negociación y aprobación de los cambios a la constitución, la discusión y votación de las leyes secundarias correspondientes, la instrumentación de las nuevas políticas y la evaluación de sus efectos. Se trata pues de un ciclo cuya duración rebasa por mucho los pocos meses que lleva el gobierno del PRI en el poder.

Sin embargo, queda claro que el diagnóstico del equipo gobernante en cuanto a la eficacia del sistema democrático coincide parcialmente con la reflexión desarrollada en las páginas anteriores, por lo menos en lo que atañe a la capacidad del Estado y al desempeño de los gobiernos democráticos. La cuestión de los derechos civiles, del Estado de derecho y del cambio de las prácticas 
y valores está presente, pero ocupa un lugar más bien secundario en esa evaluación.

El fortalecimiento del Estado y de su capacidad reguladora pasa en parte por una reivindicación nostálgica de las formas institucionales anteriores en donde la Secretaría de Gobernación (el Ministerio del Interior) vuelve a ocupar un lugar central en el aparato estatal. No sólo se trata de recuperar la dimensión mítica de esa súper secretaría encargada de supervisar la política doméstica, sino también de volver a concentrar en ella las funciones de mantenimiento de la seguridad y orden internos como en el tiempo del Antiguo Régimen. Esa reminiscencia de la idea de un Estado fuerte se ve acompañada por un discurso y acciones que apuntan hacia el fortalecimiento de la función rectora de ese mismo Estado como lo ha mostrado la acción del gobierno frente a algunos de los actores sociales que presumían una importante capacidad de bloqueo de los intentos de transformación de la vida pública. Es en ese sentido que debemos interpretar el arresto y encarcelamiento en febrero de 2013 de la líder del poderoso Sindicato Nacional de los Trabajadores de la Educación (SNTE), Elba Esther Gordillo, quien se oponía a una iniciativa presidencial de reforma constitucional en el sector de la educación pública. De la misma manera, la presentación y aprobación de una reforma constitucional en el sector de las telecomunicaciones fueron interpretadas como una afirmación de la autoridad estatal frente a los importantes consorcios de la televisión, Televisa y Tv Azteca, y de la telefonía, Telmex. ${ }^{24}$ Más allá del contenido mismo de las reformas, se trataba de mostrar la fuerza de los poderes públicos frente a los "poderes fácticos" que ponían en evidencia la débil capacidad regulatoria del Estado democrático en una situación de pluralismo asimétrico. Desde luego, por el momento, lo único que se puede apreciar es la dimensión simbólica de esos gestos. Habrá que esperar para poder evaluar plenamente

${ }^{24}$ En pocas palabras, el tema central de la reforma de la educación pública es el control de la evaluación del personal docente y de la distribución de los puestos de trabajo, mientras que la reforma del sector de las telecomunicaciones está asociada al incremento de la competitividad en el sector y al otorgamiento de los permisos de explotación. 
el alcance de esas medidas y su efecto sobre el fortalecimiento de las instituciones políticas. ${ }^{25}$

Quizás, la respuesta más interesante del gobierno con respecto a su evaluación de las dificultades de funcionamiento del sistema democrático tiene que ver con la colaboración legislativa entre los grandes partidos políticos en torno a lo que definí como las reformas esenciales que necesita el país. En efecto, las elecciones legislativas de julio de 2012 produjeron de nuevo resultados en los cuales ningún partido podía ostentar una mayoría en la Cámara de Diputados (cuadro 10). Esto significa que una vez más se iba a reproducir la situación de gobierno dividido que prevalece desde 1997 y no permite al presidente en ejercicio gozar de una mayoría legislativa.

Un año antes, en el momento de discutir una reforma política propuesta por el entonces presidente Calderón, los diputados del PRI cercanos al precandidato Peña Nieto abogaron en favor de la reintroducción en la legislación de una cláusula de gobernabilidad que permitiría la constitución de una mayoría artificial para el partido con el mayor número de votos en las dos cámaras. La iniciativa no prosperó. Más bien, el 2 de diciembre de 2012, un día después de la toma de posesión del nuevo gobierno, se anunció la firma de un Pacto por México endosado por los tres principales partidos políticos, el PRI, el PRD y el PAN. ${ }^{26}$

El pacto consiste en 95 compromisos legislativos con un calendario preciso para su realización, a los cuales suscriben los firmantes para definir la agenda legislativa de los próximos tres años. La administración de esos acuerdos se pone en manos de un consejo rector integrado por representantes de la dirigencia de los partidos participantes. Hay así un desplazamiento del eje de negociación

${ }^{25}$ En el momento de escribir estas líneas, no queda muy claro que las relaciones entre el Sindicato Nacional de Trabajadores de la Educación y el gobierno hayan cambiado, y es difícil apreciar los alcances de la aplicación de la reforma educativa en muchos estados. De la misma manera, la discusión de la ley secundaria en materia de telecomunicaciones sigue en medio de críticas al efecto de que la iniciativa del poder ejecutivo es demasiado favorable a los grandes grupos de telecomunicación.

${ }^{26}$ Meses después, el Partido Verde Ecologista de México, aliado electoral del PRI en las elecciones de 2012, se adheriría también al Pacto. 
entre el poder ejecutivo y los partidos de oposición del recinto legislativo hacia las dirigencias partidistas. Entre los compromisos asumidos, hay reformas importantes en los sectores de la educación, de la fiscalidad, de las telecomunicaciones, de la energía y de las instituciones y procedimientos políticos, es decir muchas de las reformas consideradas como esenciales. Un antecedente importante a ese nuevo espíritu de cooperación legislativa en torno a temas esenciales ha sido la aprobación de una reforma mayor a la legislación laboral (reforma que estaba en la agenda pública desde hace más de veinte años) durante la primera sesión de la nueva legislatura que se había iniciado el 1 de septiembre de 2012.

¿Cómo explicar ese nuevo espíritu de colaboración legislativa y por qué funcionó cuando intentos similares por parte de los gobiernos de Acción Nacional fracasaron?

Primero, la idea misma del Pacto político en torno a una agenda global o a un "proyecto nacional" tenía raíces profundas tanto en el PRI como en el PRD. Por lo menos, era la solución que esos partidos proponían reiteradamente frente al bloqueo legislativo incluso si no estaban dispuestos a ponerla en vigor durante los gobiernos del Pan. Por parte del Pan, muchos de los 95 compromisos eran parte de su agenda política. Además, la idea de una democracia de consenso global (en contraste a una democracia de mayoría cambiante) tiene mucho arraigo en la cultura política nacional.

La coyuntura política postelectoral se prestaba también a la firma de ese acuerdo sobre todo en lo que se refiere a la vida interna de los dos grandes partidos de oposición. En efecto, tanto la dirigencia del Partido Acción Nacional como la del Partido de la Revolución Democrática se enfrentaban a tensiones muy fuertes en el seno de sus respectivas organizaciones partidistas. En el PAN, el presidente Madero tenía la oposición de los antiguos cuadros del gobierno calderonista cuya inconformidad desembocará meses después en una rebelión de algunos de los senadores del partido en contra de la estrategia de la dirigencia. En el PRD, el presidente Zambrano tenía que hacer frente al proceso de separación y creación de un nuevo partido por los seguidores del candidato presidencial de la izquierda derrotado en las elecciones de 2012, Andrés Manuel López Obrador. En ambos casos, los resultados del Pacto 
podían servir de legitimación a las dirigencias partidistas frente a sus adversarios internos. De la misma manera, la dinámica de funcionamiento de ese mecanismo de concertación les permitía mantenerse también en el centro de la vida pública nacional. Finalmente, la participación en ese acuerdo constituía un instrumento de vigilancia y de presión constante de la oposición sobre la acción del gobierno como se mostró meses después cuando los partidos de oposición denunciaron el uso clientelar de recursos públicos por parte del gobierno priista de Veracruz y amenazaron con dejar el Pacto si no se controlaban esas prácticas por parte del gobierno. Desde luego, en una perspectiva más positiva, uno podría ver en ese acercamiento entre partidos el inicio de un esfuerzo para definir conjuntamente un esbozo de definición del bien común más allá de las diferencias entre adversarios.

En sus pocos meses de existencia, el Pacto por México ha logrado producir reformas constitucionales de envergadura, reformas que eran parte de la lista de las iniciativas legislativas consideradas como sujetas a bloqueo y polarización entre las diversas fuerzas políticas y grupos de interés: las reformas de los sectores de la educación, de las telecomunicaciones, de la fiscalidad, del sector energético y de las instituciones electorales. Como ya se mencionó, es sólo una parte inicial del proceso de elaboración de las políticas públicas y, por ello, todavía falta mucho para considerar que se trata de un proceso en materia de colaboración legislativa. Pero, en el plano simbólico, esas iniciativas muestran que el pluralismo no es sinónimo de ineficiencia política. La verdadera prueba para el Pacto se dio en el momento de discutir las leyes secundarias que permiten la aplicación práctica de las reformas. Ahí, como se pudo observar en el primer semestre de 2014, el aliento de colaboración legislativa se fue agotando. De hecho, a partir de enero de 2014, el mecanismo del Pacto se fue desvaneciendo al punto de desaparecer sin que se pusiera formalmente fin a su existencia.

El fortalecimiento de la capacidad del Estado no pasa solamente por la realización de acciones espectaculares frente a grupos de interés poderosos o por la reivindicación de un modelo de organización que trae recuerdos de un aparato estatal con mayor poder despótico, para retomar un concepto de Michael 
Mann. Como ya se estableció anteriormente, la fortaleza del Estado democrático pasa obligatoriamente por la consolidación del Estado de derecho. En ese campo, existen desafíos enormes. Uno de ellos está relacionado como lo hemos visto al funcionamiento del sistema judicial. En 2008, se aprobó una importante reforma judicial en materia de derecho penal que tiene entre otros objetivos la homologación de los códigos criminales en toda la federación y la introducción del procedimiento del juicio oral. El horizonte de aplicación de la reforma en todo el territorio nacional es 2016. Se supone que su entrada en vigor contribuirá a hacer que la impartición de justicia sea más eficiente y más expedita. Hasta ahora, encontramos referencias frecuentes a la necesidad de pronta adecuación de los códigos penales estatales a la reforma nacional en el discurso del nuevo gobierno. ¿Es suficiente para comprobar el compromiso del gobierno del PRI con el Estado de derecho? Desde luego que no. La demostración de ese compromiso se dará fundamentalmente con el despliegue de la estrategia del gobierno en su lucha contra el narcotráfico y la violencia que está asociada con ella. Por el momento, si bien hay un cambio en el discurso sobre ese grave problema y anuncios de intenciones de reorientación de las políticas, existen pocos elementos para juzgar la acción del gobierno. La intervención del gobierno federal en el estado de Michoacán para hacer frente a los grupos de narcotraficantes y permitir la reinserción de los grupos de autodefensa en el marco institucional mostró una gran capacidad de negociación política a la antigua, pero difícilmente constituye en este momento una medida de fortalecimiento del Estado de derecho.

Por fin, una última dimensión vinculada a la calidad de la vida democrática tiene que ver con los valores y las prácticas. No basta con reformar las instituciones para cambiar los comportamientos. Uno de los temores suscitados por la victoria del PRI es la reafirmación de una manera de hacer política propia del pasado autoritario del país. Si bien el PRI no es el único partido portador de esa cultura política, es el que la pone en práctica de la manera más natural, o por lo menos así se piensa en el imaginario colectivo nacional. Habrá que ver qué actitud adoptará el nuevo gobierno ante casos de corrupción de los miembros del partido -en este 
momento hay por lo menos dos exgobernadores bajo escrutinio público y mediático por ese motivo- o de prácticas clientelares con recursos públicos o de actos de gobierno arbitrarios. Si bien el contexto democrático que resulta de los cambios por los cuales atravesó el sistema político en los últimos años constituye una limitación al regreso a prácticas del pasado, los actos del propio gobierno deberán contribuir también a evitar esas prácticas.

\section{Conclusiones}

A manera de conclusión, es posible afirmar que la situación de la democracia en México no es de ninguna manera catastrófica, aun si un "suave desencanto" con la democracia flota en la vida pública. Como sabemos, las democracias pueden sobrevivir de esta manera durante años, si bien, ciertamente, no es éste el camino para producir democracias vigorosas: cualquier acontecimiento imprevisto puede poner en evidencia la fragilidad de los arreglos democráticos.

A fin de superar las dificultades señaladas en este texto, se requeriría, en primer lugar, un aprendizaje que amplíe el horizonte temporal de la vida democrática y permita superar el actual ciclo que va de contienda electoral en contienda electoral. En ese sentido, es interesante constatar la aparente conciencia por parte de la clase política nacional de la necesidad de encontrar mecanismos para privilegiar acuerdos en torno a la resolución de problemas nacionales fundamentales. El contenido del Pacto por México firmado por las tres principales formaciones políticas muestra la existencia de un diagnóstico compartido en torno a esos grandes problemas y a las reformas necesarias para intentar darles una solución, incluso si queda por definir su contenido exacto y sus modos de implantación. Es un primer paso en la buena dirección. Ojalá prevalezca una concepción compartida del bien público que sea suficientemente resistente para sobrevivir los azares de la lucha política dentro y fuera de los partidos políticos. Este mecanismo podría permitir el fortalecimiento de la capacidad del Estado democrático mediante la coordinación de los diversos segmentos del 
sistema político. Es muy pronto para evaluar los efectos de ese artefacto para facilitar la colaboración política entre adversarios en un contexto de competencia democrática. Además, para responder a las dificultades estructurales de la nueva democracia mexicana descritas en este capítulo, se requiere la adopción de un número importante de reformas relacionadas tanto con los arreglos institucionales que sustentan el aparato de Estado como con políticas cuyo objetivo contribuya a fortalecer la capacidad de ese mismo Estado. Es un proceso largo y accidentado. En el campo de los derechos de diversa naturaleza y de la ciudadanía, la promoción de valores y prácticas democráticas es un elemento fundamental para el robustecimiento de un Estado de misma naturaleza. De la misma manera en que el régimen autoritario se apoyaba en arreglos informales, hay que fortalecer la informalidad propia a unos arreglos institucionales democráticos. Si bien es un empeño que corresponde al conjunto de la clase política y de la sociedad, no deja de ser paradójico que para los próximos años el gobierno responsable de esa tarea sea un gobierno del Partido Revolucionario Institucional.

\section{Bibliografía}

Banco Mundial, Annual percentage growth rate of GDP, en http:/ / data.worldbank.org/country/mexico

Bizberg, I., "La crisis del corporativismo en México", Foro Internacional, vol. 30, núm. 4, 1990.

Casar, M. A., "Executive-Legislative Relations: Continuity or Change?”, en A. Selee y J. Peschard (eds.), Mexico's Democratic Challenges: Politics, Government and Society, Washington y Stanford, Woodrow Wilson Center Press-Stanford University Press, 2010, pp. 117-134.

, "Representation and Decision Making in the Mexican Congress", México, cIDE, Working Paper, núm. 258, 2011.

cepalstat, Índice de concentración de Gini, en http://interwp.cepal. org/sisgen/ConsultaIntegrada.asp

CIDAC, Red Numbers of the Criminal Justice System in Mexico, México, octubre de 2011, en http://cidac.org/esp/uploads/1/Red_Numbers.pdf 
Coneval, Análisis y medición de la pobreza, en http://www.coneval.gob. $\mathrm{mx} /$ Medicion/Paginas/Evolucion-de-las-dimensiones-de-la-pobreza-1990-2010-.aspx

Córdova, A., La revolución y el Estado en México, México, Era, 1989.

De la Peña, G., "Poder local, poder regional: perspectivas socio-antropológicas”, en J. Padua y A. Vanneph, Poder local, poder regional, México, El Colegio de México-Cemca, 1988, pp. 27-58.

Esquivel, G., "De la inestabilidad macroeconómica al estancamiento estabilizador: el papel del diseño y la conducción de la política económica”, en N. Lustig (coord.), Crecimiento económico y equidad. Los grandes problemas de México, IX, México, El Colegio de México, 2010, pp. 35-78.

Escalante Gonzalbo, F., "Homicidios 2008-2009. La muerte tiene permiso", Nexos en línea, enero de 2011.

Hernández Rodríguez, R. y W. Pansters, "La democracia en México y el regreso del PRI", Foro Internacional, vol. 52, núm. 210, 2012, pp. 755-795.

IFE, Estadística y resultados electorales, en http://www.ife.org.mx/portal/ site/ifev2/Estadisticas_y_Resultados_Electorales/

INEGI, "Defunciones por homicidio 1990-2011", en http:/ / www.inegi.org. $\mathrm{mx}$

Latinobarómetro, Informe Latinobarómetro 2011, Santiago de Chile, 28 de octubre de 2011, en http://www.infoamerica.org/primera/lb_2011. pdf

Latinobarómetro, Informe Latinobarómetro 2013, Santiago de Chile, 1 de noviembre de 2013, en http://www.latinobarometro.org/documentos/LATBD_INFORME_LB_2013.pdf

Levitsky, S. y L. S. Way, Competitive Authoritarianism: Hybrid Regimes after the Cold War, Cambridge, Cambridge University Press, 2010.

Lijphart, A., Patterns of Democratic Government. Forms and Performance in the Thirty-Six Countries, New Haven y Londres, Yale University Press, 1999.

Loaeza, S. y J. F. Prud'homme (coords.), Instituciones y procesos políticos. Los grandes problemas de México, México, El Colegio de México, 2010.

Olvera, A., "Las tendencias generales de la sociedad civil en México", en A. Olvera (comp.), Sociedad civil, esfera pública y democratización en México, Xalapa y México, Universidad Veracruzana-FCE, 2003, pp. 42-70.

Pardo, M. C., "El Estado mexicano: ¿de la intervención a la regulación?", en S. Loaeza y J. F. Prud'homme (coords.), op. cit., pp. 71-121. 
Political Database of the Americas, Electoral Results, en http://pdba.georgetown.edu/Elecdata/Mexico/mexico.html

Prud'homme, J. F., "Los partidos políticos”, en S. Loaezay J. F. Prud'homme (coords.), op. cit., pp. 121-158.

Puhle, H.-J., "Problemas de consolidación democrática y democracias defectuosas", en W. Bernecker (comp.), Transición democrática y anomia social en perspectiva comparada, México, DAAD-UnAm-El Colegio de México, 2004, pp. 15-47.

SEgob, Encuesta Nacional de Cultura Política y Prácticas Ciudadanas, México, en http://encup.gob.mx/es/Encup/Encup

SAT, Informe tributario y de gestión, México, 2005 y 2013.

shcP, "Balance Fiscal en México. Definición y Metodología”, 2013, en http:/ / www.shcp.gob.mx/POLITICAFINANCIERA/FINANZASPUBLICAS/Estadisticas_Oportunas_Finanzas_Publicas/Informacion_ mensual/Metodologia/1bfm.pdf

Somuano, M. F., "Las identidades partidistas de los mexicanos y la elección de 2012", manuscrito, 2013.

— , "Las organizaciones civiles: formación y cambio", en S. Loaeza y J. F. Prud'homme (coords.), op. cit., pp. 197-230.

Woldenberg, J., "Mi lectura de las elecciones", Letras Libres, núm. 165, septiembre de 2012. 